\title{
Prevalence of Gastrointestinal Parasites in the Frugivorous and the Insectivorous Bats in Southcentral Nepal
}

\author{
Roshan Babu Adhikari $\mathbb{D},{ }^{1,2,3}$ Mahendra Maharjan $\mathbb{D}^{2},{ }^{2}$ and Tirth Raj Ghimire $\mathbb{D}^{3}$ \\ ${ }^{1}$ Third Pole Conservancy, Wildife and Eco-health, Bhaktapur, Nepal \\ ${ }^{2}$ Central Department of Zoology, Tribhuvan University, Kathmandu, Nepal \\ ${ }^{3}$ Animal Research Laboratory, Faculty of Science, Nepal Academy of Science and Technology (NAST), Lalitpur, Nepal \\ Correspondence should be addressed to Tirth Raj Ghimire; tirth.ghimire@nast.gov.np
}

Received 27 May 2020; Revised 14 October 2020; Accepted 28 October 2020; Published 14 December 2020

Academic Editor: Emmanuel Serrano Ferron

Copyright (c) 2020 Roshan Babu Adhikari et al. This is an open access article distributed under the Creative Commons Attribution License, which permits unrestricted use, distribution, and reproduction in any medium, provided the original work is properly cited.

\begin{abstract}
Bats are the only active flying placental mammals and are traditionally classified into mega- and microbats, which are, respectively, herbivorous and insectivorous in feeding habit. Though deforestation, habitat destruction, natural calamities, illegal hunting, and climate changes are the challenging threats for bats, the role of existing gastrointestinal (GI) parasites have not been evaluated yet in Nepal. Thus, the current study aims to determine the prevalence of GI parasites in bats from the Shaktikhor area at the Chitwan district of Southcentral Nepal. From July 2018 to February 2019, a total of 60 fecal samples of bats (30 from frugivorous bats and 30 from the insectivorous bats) were collected. These samples were preserved at $2.5 \%$ potassium dichromate solution. The fecal examination was carried out by the direct wet mount, concentrations, acid-fast staining, and sporulation techniques. Overall results showed the prevalence rate of $80 \%$ GI parasites. The parasites detected in the insectivorous bats were Ascarid spp., Capillarid sp., Cryptosporidium sp., Eimeria spp., Entamoeba sp., Giardia sp., Hymenolepis spp., Isospora sp., Oxyurid sp., Strongyle, and Strongyloides sp. In contrast, Eimeria sp., Entamoeba sp., and Hymenolepis sp. were detected in the frugivorous bats. Based on a wide diversity of parasite richness and parasitic concurrency measured by the prevalence rates, we suggest that GI parasitism might be a threatening factor in the insectivorous bats in the current study area.
\end{abstract}

\section{Introduction}

Bats belonging to the order Chiroptera are the only active flying true placental mammals of the animal kingdom. Chiroptera is the second largest order of mammals (after the rodents) with cosmopolitan distribution $[1,2]$. Bats are traditionally classified into the megabats and microbats [3-5]. Megabats include flying foxes and the old-world fruit bats, which are usually herbivores and consume fruits, flowers, leaves, nectar, and pollens $[3,5,6]$. In contrast, microbats are mostly insectivorous in feeding habits; although, few of these species may feed on blood, fruits, nectars, pollens, and vertebrates $[3,7-10]$.

It has been estimated that more than 1300 species of bats are reported in the world $[1,8]$. However, many species are threatened with extinction globally, and more than 280 species are categorized as endangered, vulnerable, or near threat- ened by the IUCN Red List [11]. In the context of Nepal, there are a total of 54 bat species belonging to seven different families indicating this Himalayan nation to be one of the rich countries in their diversities [12]. However, deforestation, habitat destruction due to the operation of road construction projects and natural calamities, illegal hunting, and climate changes exist as challenging threats for these mammals [13]. Among these threatening factors, diseases might be critical because these mammals play roles as pathogen carriers, reservoirs, and transmitters in nature. The disease-causing pathogens are viruses, bacteria, fungi, and parasites, which can be life threatening in humans and animals. It should be noted that several species of gastrointestinal (GI) protozoa, trematodes, nematodes, and cestodes have been predominantly reported from the bats of various geographies, and they may remain as one of the major threats for their lives [14-21]. Moreover, infected bats act as 
definitive or intermediate or a paratenic host for many protozoan, trematode, cestode, and nematode parasites [21]. In these situations, feeding behavior, biological, and ecologic diversity of bats might play a critical role in the hostparasite interactions and parasitism [21]. However, the study of these parasitic faunae in bats has been still at virgin state in Nepal. Besides, the association of GI parasitism based on the feeding ecology of bats has not been determined and compared so far. Thus, in this study, we have investigated the prevalence of GI parasitic species in the frugivorous and the insectivorous bats found in Chitwan, the Southcentral part of Nepal.

\section{Materials and Methods}

2.1. Study Area. The current study was conducted in ward no. 9 and 10 of Kalika Municipality, the commonly called Shaktikhor area (251 m to $1003 \mathrm{~m}$ above sea level, asl) (Figure 1). The geographic locations range from (27.69544-27.73472) N to (84.57159-84.65498) E in Chitwan district, in the Southcentral part of Nepal. It is 182 kilometers (kms) away from the capital city and is linked to the East-West highway by road up to the foothills. The climate is tropical to subtropical, with an average annual temperature of $29.30^{\circ} \mathrm{C}$ during summer and $9.4^{\circ} \mathrm{C}$ during winter. Similarly, the yearly average rainfall is $1993 \mathrm{~mm}$ [22]. The vegetation of this area includes lowland Sal forest, hill Sal forests, tropical riverine forest, tropical mixed broad-leaved forest, and subtropical mixed forest [23], and a total of 13 species of birds, eight species of mammals, and six species of reptiles have been reported to inhabit this area according to the Environmental Impact Assessment done in 2019 [22].

2.2. Sample Collection, Preservation, and Transportation. A total of 60 fecal samples (30 from the frugivorous and 30 from the insectivorous bats) were collected from July 2018 to February 2019 from the study area. The frugivores included Rousettus leschenaulti and Eonycteris spelaea and insectivores included Rhinolophus macrotis, Rhinolophus pusillus, and Rhinolophus pearsonii [13] (Figure 2). For fecal sample collection, 30 frugivorous bats were captured using the net at night time from five different spots in the butter tree (Diploknema butyracea) forest, and anal swabbing was performed with the help of cotton buds. In the context of the insectivorous bats, a total of 30 clean white plastic were overlaid on the floor of five different caves (six plastics per cave) just below their roosts in the morning. The fecal samples that fell down the plastic were collected with the help of forceps in the evening. Quality control during sample collection was performed by observing the absence of other mammals inside the wet and dark caves. The collected samples were immediately preserved at $2.5 \%$ potassium dichromate solution in $20 \mathrm{~mL}$ sterile vials. They were transported to Animal Research Laboratory (ARL) of the Nepal Academy of Science and Technology (NAST) and further stored at 4 degrees $\left({ }^{\circ}\right)$ Celsius temperature.

2.3. Laboratory Processing and Examination. The fecal samples were macroscopically examined for the presence of blood, mucus, segments of cestodes, as well as whole adult nematodes and microscopically examined by the techniques based on the literatures, explained previously [24, 25].

2.3.1. Direct Wet Mount Technique. One to two drops of carefully stirred fecal samples were put in the slide with the help of a plastic dropper. The samples were observed directly at $2.5 \%(w / v)$ potassium dichromate, Gram's iodine stain, and Giemsa's stain (1/15).

2.3.2. Saturated Salt Floatation Technique. About two grams (gms) of the fecal samples were thoroughly mixed in a 13 milliliter $(\mathrm{mL})$ normal saline $(0.9 \% \mathrm{w} / \mathrm{v})$ solution and filtered with the help of a tea strainer. The solution was poured into a $15 \mathrm{~mL}$ conical centrifuge tube and proceeded to centrifuge (1200 revolutions per minute, rpm for 5 minutes). After discarding the supernatant, $12 \mathrm{~mL}$ of salt solution $(45 \% \mathrm{w} / \mathrm{v})$ was added and proceeded to centrifuge (1200 rpm for 5 minutes). Then, few drops of salt solution $(45 \% \mathrm{w} / \mathrm{v})$ were added in the tube to fill it, and a coverslip was placed on the mouth of the tube. After 10 minutes, the coverslip was carefully removed and put on the glass slide with or without Lugol's iodine for microscopic observation at 100x and 400x total magnifications.

2.3.3. Sedimentation Technique. About two gms of the fecal samples were thoroughly mixed in $13 \mathrm{~mL}$ normal saline $(0.9 \% w / v)$, were filtered with the help of a tea strainer into a $15 \mathrm{~mL}$ centrifuge tube, and were proceeded to centrifuge (1200 rpm for 5 minutes). Then, the supernatant was discarded, and one to two drops of the sediment was put on a glass slide. Gram's iodine and Giemsa's stain (1/15 dilutions) were differently used in the deposits for the microscopic examinations at $100 \mathrm{x}$ and $400 \mathrm{x}$ total magnifications.

2.3.4. Acid-Fast Staining. About one gm of the Cryptosporidium-positive sediments, $10 \% 10 \mathrm{~mL}$ formalin, and $4 \mathrm{~mL}$ ethyl acetate were taken in a $15 \mathrm{~mL}$ centrifuge tube and proceeded to centrifuge (1200 rpm for 5 minutes). Then, the supernatant was discarded, and the sediments were used to prepare thin smears. This smear was allowed to dry at room temperature and then fixed in the absolute methanol for 2 minutes. The smear was stained with carbol fuchsin for 15 minutes at room temperature and then washed with distilled water followed by destaining with acid alcohol, and finally rinsed with distilled water. The smear was further restained with malachite green for one minute, followed by washing with distilled water, and allowed to dry at room temperature. The dry slide was observed at 1000x total magnification using immersion oil.

2.3.5. Sporulation Assay. About two gms of coccidian positive samples were incubated at equal volumes of $2.5 \%$ potassium dichromate at $28^{\circ} \mathrm{C} \pm 1$ temperature in an incubator for sporulation assays. Then, using the floatation method, the sporulation states were observed at each 24 hours interval under the microscope [26-28]. The presence of oocysts of Eimeria spp. and Isospora sp. was confirmed by their respective spore formulas as 0.4.2 and 0.2.4, as reviewed previously [29]. 


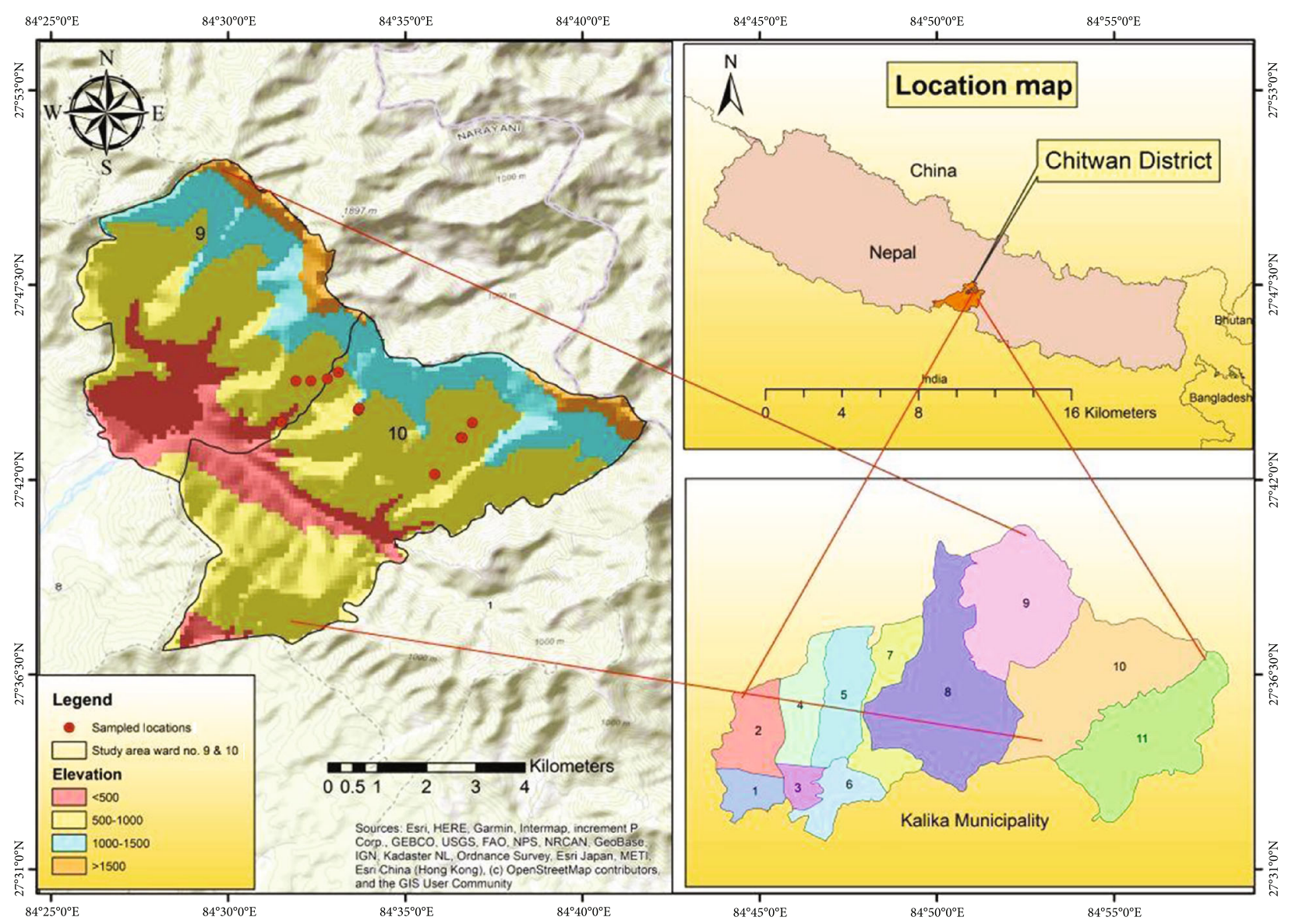

FIGURE 1: Map of the study area showing the locations of sample collections.

2.3.6. Parasite Identification. All the fecal parasites were carefully observed under a light microscope (Optika Microscopes Italy, B-383PLi) at a total magnification of $100 \mathrm{x}, 400 \mathrm{x}$, and 1000x. Photographs were taken by the camera (SXView 2.2.0.172 Beta (Nov 6, 2014) Copyright (C) 2013-2014) accompanied by the microscope. The size of the parasites was assessed by using ImageJ 1.51k (National Institute of Health, USA), and identification was carried out based on various literature [30-36].

2.4. Data Analysis. Data were expressed as numbers of positive samples as well as prevalence rates in the table using Microsoft Word. Prevalence rates were calculated by dividing the number of GI positive samples (total or particular species) by the total number of samples observed [24]. We used the GraphPad Software (Prism 5 for Windows Version 5.00 @ 1992-2007 GraphPad Software, Inc). We applied Fisher's exact test (two-sided) to assess $p$ values by comparing the prevalence of specific GI parasitic groups between the frugivorous bats and the insectivorous bats. Statistical significance was considered at the $95 \%$ confidence interval $(\alpha=0.05$, $p<0.05)$.

\section{Results}

In the current study, out of 60 fecal samples, $80 \%$ (60\% in the frugivorous and $100 \%$ in the insectivorous bats) were positive for at least one GI parasitic species. The sensitivity of different tests gave different results, for example, direct wet mount, sedimentation, and flotation techniques detected GI parasites in $61.7 \%(37 / 60)$ with seven species, $73.3 \%$ (44/60) with nine species, and $76.7 \%(46 / 60)$ with nine species, respectively. The overall prevalence of protozoan and helminth parasites was $70 \%$ and $50 \%$, respectively. In this context, the prevalence of protozoa was double ( $93 \%$ versus $46.7 \%)(p<0.0001)$, and that of helminths was four times greater $(80 \%$ versus $20 \%)(p<0.0001)$ in the insectivorous bats compared to the frugivorous bats. The prevalence of specific GI parasites in frugivores was Entamoeba sp. (40\%), Eimeria sp. (13.3\%), and Hymenolepis sp. (20\%). In contrast, the insectivores possessed Eimeria spp. (83.3\%), Strongyle (56.7\%), Hymenolepis spp. (50\%), Entamoeba sp. (30\%), Isospora sp. (16.7\%), Strongyloides sp. (16.7\%), Ascarid spp. (16.7\%), Cryptosporidium sp. (10\%), Oxyurid sp. (6.7\%), Giardia sp. (3.3\%), and Capillarid sp. (3.3\%) (Figure 3) (Table 1).

Further, we classified Eimeria spp. into six different morphologic forms in the insectivorous bats; however, a single morphotype of this coccidian was present in frugivores. Similarly, in the context of helminths, six species of parasites were found in the insectivorous bats, but only one Hymenolepis sp. was detected in the frugivorous bats. In frugivores, the eggs of Hymenolepis sp. were light purple (average size ranges: $42-48 \mu \mathrm{m} \times 40-46 \mu \mathrm{m}$ ). In contrast, the eggs were 


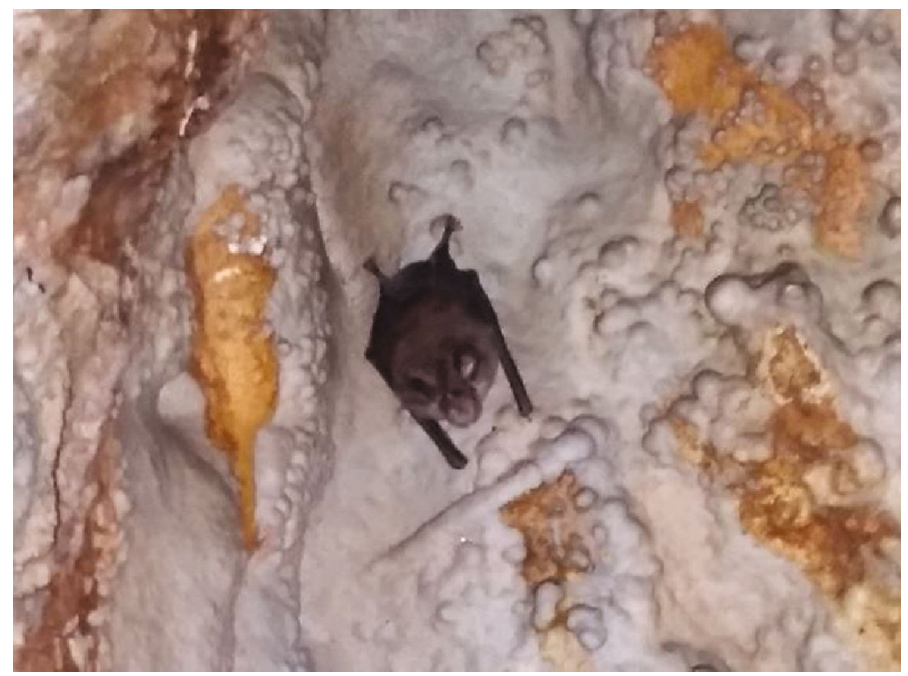

(a)

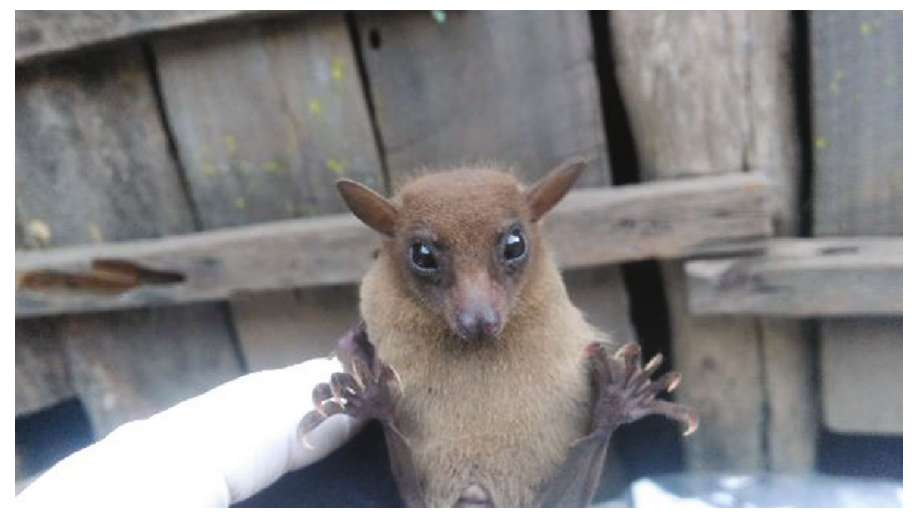

(b)

Figure 2: (a) Photograph of an insectivorous bat in the tunnel. (b) Photograph of a frugivorous bat.

light purple as well as dark brown (average size range of $48-66 \mu \mathrm{m} \times 39-62 \mu \mathrm{m})$ in the insectivores. In the insectivorous bats, a total of three samples were positive for eggs similar to human Ascaris, and one sample was positive for eggs similar to Toxocara pteropodis. Therefore, we named Ascarid spp. to the Ascaris-like and Toxocara pteropodis-like eggs detected. Similarly, three morphotypes (size ranges: $58-92 \mu \mathrm{m} \times 25-58 \mu \mathrm{m}$ ) of the eggs of Strongyle were identified in the insectivorous bats (Figure 3 ).

The concurrency of the GI parasitism in the fecal samples was also analyzed. Single infection was higher in the frugivorous bats than in insectivores ( $46.7 \%$ versus $13.3 \%)$. In contrast, multiple infections were significantly higher in the insectivorous bats than in frugivores (86.7\% versus $13.3 \%)$ $(p<0.0001)$. The insectivorous bats contained mixed infections up to five various species, whereas, in frugivores, we found mixed infections only up to two different species (Figure 3) (Table 1). Entamoeba showed maximum single $(57 \%)$ and double (100\%) infections in frugivorous bats. In contrast, Eimeria showed maximum single (75\%), double $(86 \%)$, triple $(100 \%)$, quadruplet $(66.7 \%)$, and pentuplet (100\%) infections in insectivorous bats (Supplementary file 1).

\section{Discussions}

To the best of our knowledge, the current study was the first attempt to investigate the prevalence study of GI parasites of bats according to their feeding habit in this Himalayan nation. The current prevalence rate of GI parasites $(80 \%)$ in bats was lower than the findings from France (100\%) [37], Brazil (96.29\%) [34], Serbia (88.2\%) [20], and South Africa (85.5\%) [38]; slightly higher than those recorded from Argentina (78.6\%) [39], Nigeria (76.78\%) [40], England (76\%) [41], and Mexico (72-76\%) [42, 43]; and higher than those from the United States (63.6-75\%) [15,44] and Egypt (43.5\%) [45]. These differences might be attributed to the application of different sampling techniques in the field, different methods in different laboratories, and climatic scenarios in the various study sites. The current study used the direct wet mount, concentration techniques, acid-fast staining, and sporulation assays that might have produced high positive cases. Besides, few factors like pathogen-harboring nature, colonizing or aggregating behaviors, and species of the bats [46-51] might also differently govern parasitic infectiousness. Except for the report of Lima and colleagues [34] 


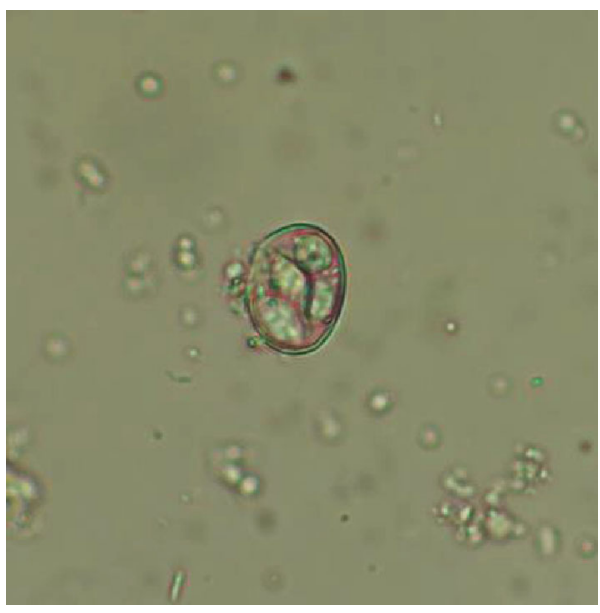

(a)

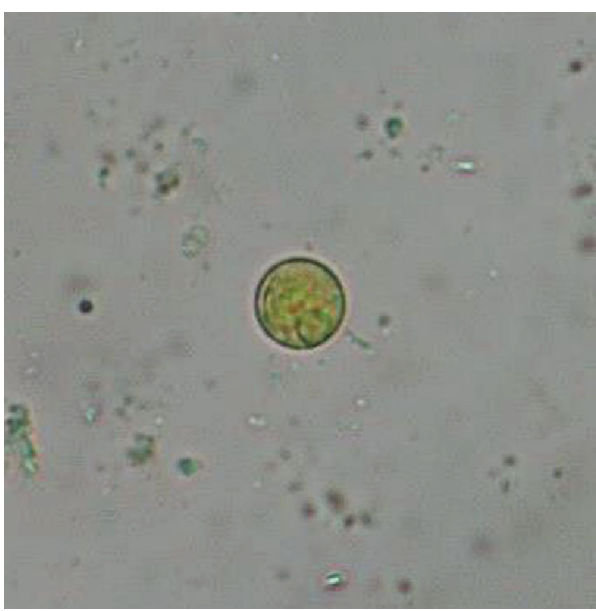

(c)

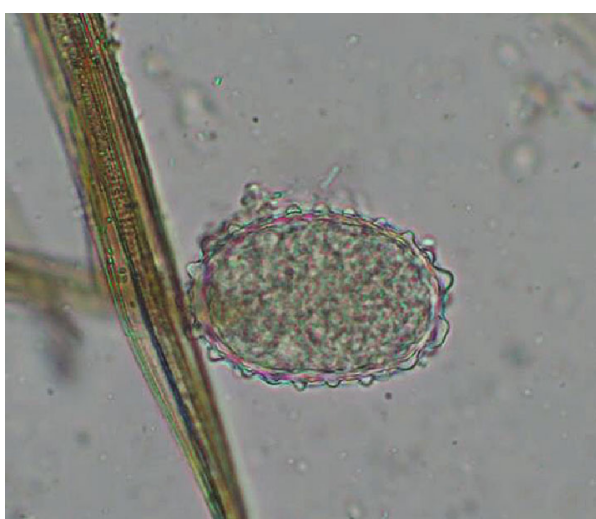

(e)

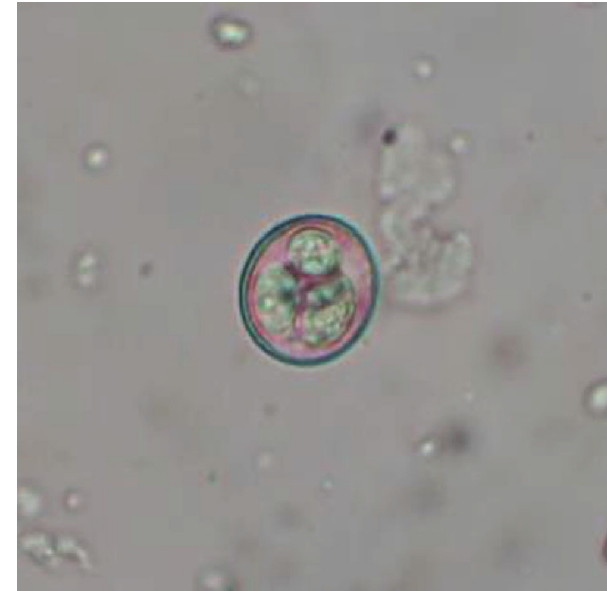

(b)

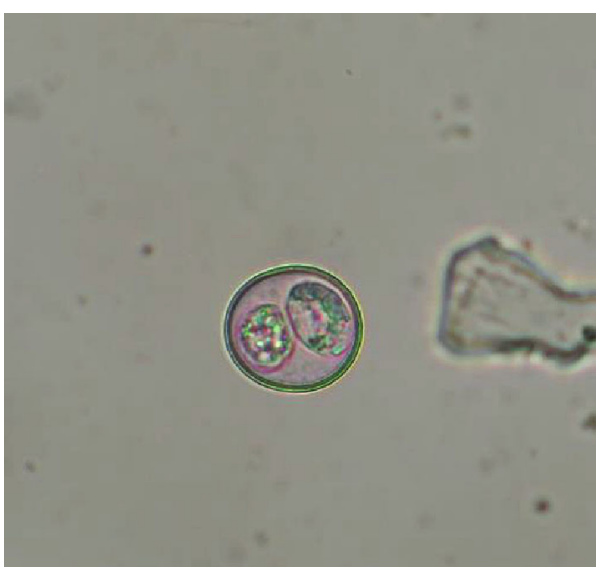

(d)

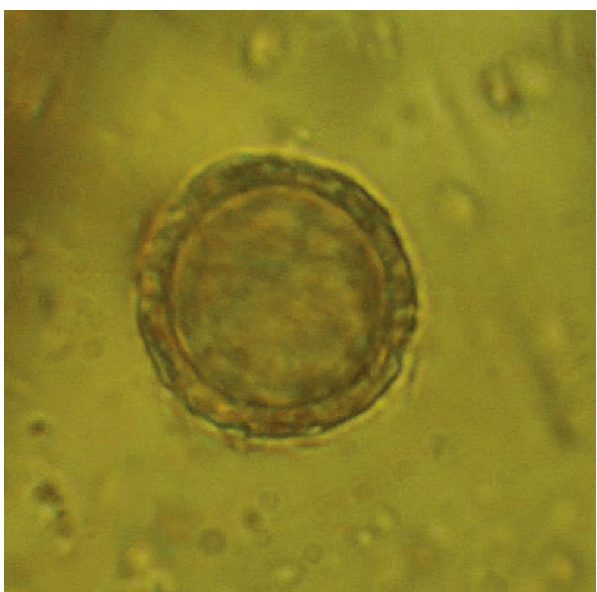

(f)

Figure 3: Continued. 


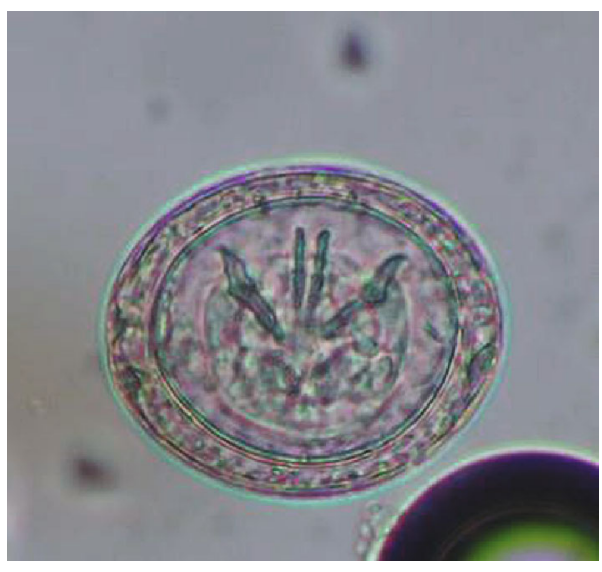

(g)

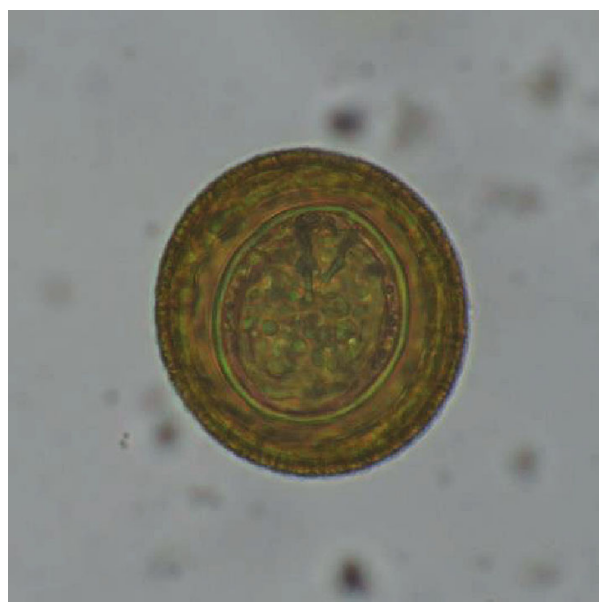

(i)

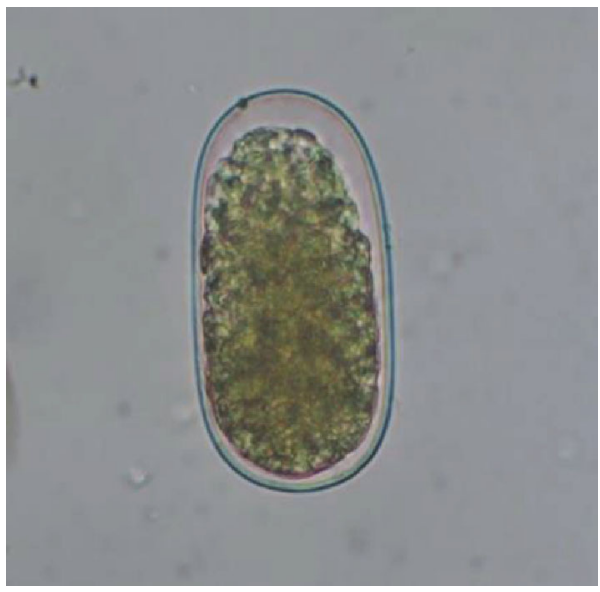

(k)

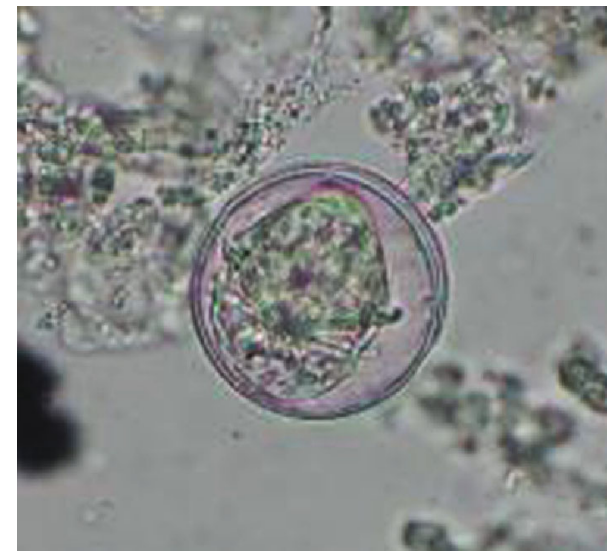

(h)

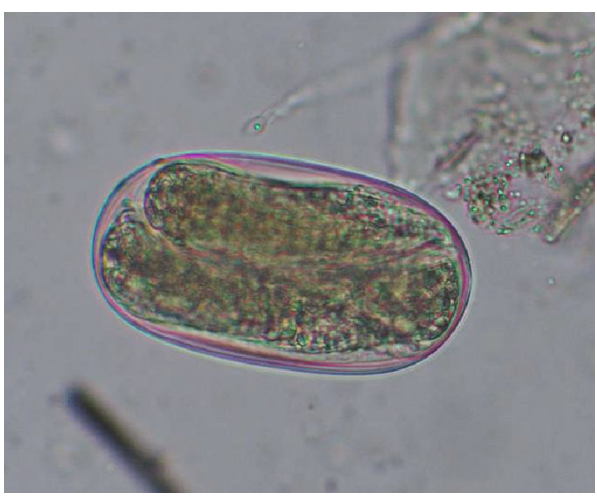

(j)

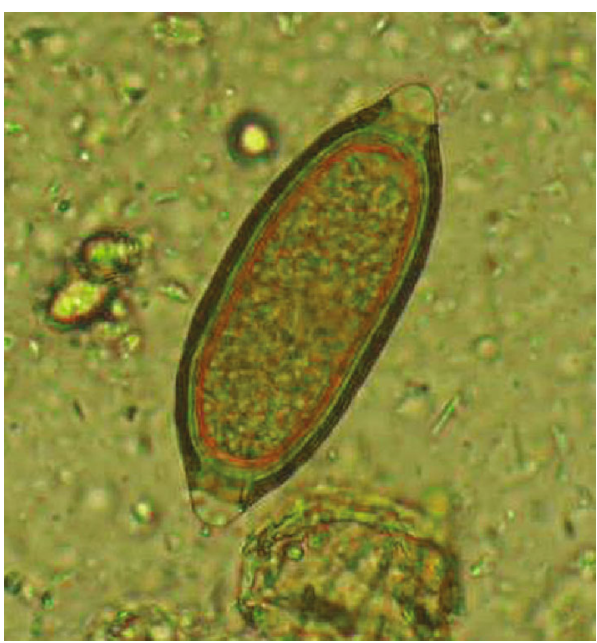

(l)

Figure 3: Continued. 


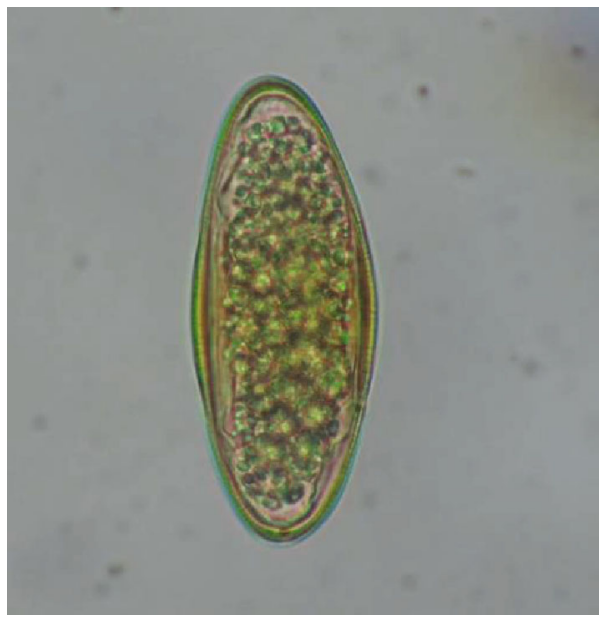

$(\mathrm{m})$

FIgURE 3: Photomicrographs of various parasitic species. (a) Oocyst of Eimeria sp. (i) $(20 \times 14 \mu \mathrm{m})$, 400x, direct wet mount at Gram's iodine stain, in insectivorous bat. (b) Oocyst of Eimeria sp. (ii) $(17 \times 15 \mu \mathrm{m}), 400 \mathrm{x}$, after flotation technique at Giemsa's stain, in insectivorous bat. (c) Cyst of Entamoeba sp. $(11 \times 11 \mu \mathrm{m}), 400 \mathrm{x}$, direct wet mount at Lugol's Iodine stain, in insectivorous bat. (d) Oocyst of Isospora sp. $(25 \times 23$ $\mu \mathrm{m}), 400 \mathrm{x}$, after flotation technique, in insectivorous bat. (e) Egg of Ascarid sp. $(54 \times 36 \mu \mathrm{m}), 400 \mathrm{x}$, after sedimentation technique at Giemsa's stain, in insectivorous bat. (f) Egg of Toxocara sp. $(50 \times 49 \mu \mathrm{m}), 400 \mathrm{x}$, direct wet mount at $2.5 \%$ potassium dichromate, in insectivorous bat. (g) Light purple-colored egg of Hymenolepis sp. $(52 \times 43 \mu \mathrm{m}), 400 \mathrm{x}$, after flotation technique, in insectivorous bat. (h) Egg of Hymenolepis sp. $(44 \times 43 \mu \mathrm{m}), 400 \mathrm{x}$, after flotation technique, in frugivorous bat. (i) Brown-colored egg of Hymenolepis sp. $(65 \times 62 \mu \mathrm{m})$, $400 \mathrm{x}$, after flotation technique in insectivorous bat. (j) Egg of Strongyloides sp. $(87 \times 46 \mu \mathrm{m}), 400 \mathrm{x}$, after sedimentation technique at Gram's iodine stain, in insectivorous bat. (k) Egg of Strongyle $(83 \times 41 \mu \mathrm{m}), 400 \mathrm{x}$, after flotation technique, in insectivorous bat. (l) Egg of Capillarid sp. $(67 \times 25 \mu \mathrm{m})$, $400 \mathrm{x}$, direct wet mount at $2.5 \%$ potassium dichromate, in insectivorous bat. (m) Egg of Oxyurid sp. $(93 \times 36 \mu \mathrm{m}), 400 \mathrm{x}$, after flotation technique, in insectivorous bat.

TABle 1: Parasitic species, their concurrency, and prevalence in the frugivorous and insectivorous bats in Southcentral Nepal. Fisher's exact test (two-tailed) was used to calculate the $p$ values by comparing the prevalence rates of different parasitic species or groups between the frugivores and insectivores.

\begin{tabular}{|c|c|c|c|c|}
\hline Parasitic infections & $\begin{array}{c}\text { Frugivores }(N 1=30) \\
\text { Prevalence }(n \times 100 / N 1)\end{array}$ & $\begin{array}{c}\text { Insectivores }(N 2=30) \\
\text { Prevalence }(n \times 100 / N 2)\end{array}$ & Overall $(N=60)$ prevalence $(n \times 100 / N)$ & $p$ values \\
\hline Entamoeba sp. & $12(40 \%)$ & $9(30 \%)$ & $21(35 \%)$ & \multirow{6}{*}{$p<0.0001$} \\
\hline Eimeria spp. & $4(13.3 \%)$ & $25(83.3 \%)$ & $29(48.3 \%)$ & \\
\hline Isospora sp. & 0 & $5(16.7 \%)$ & $5(8.3 \%)$ & \\
\hline Cryptosporidium sp. & 0 & $3(10 \%)$ & $3(5 \%)$ & \\
\hline Giardia sp. & 0 & $1(3.3 \%)$ & $1(1.7 \%)$ & \\
\hline Total Protozoa & $14(46.7 \%)$ & $28(93.3 \%)$ & $42(70 \%)$ & \\
\hline Ascarid spp. & 0 & $5(16.7 \%)$ & $5(8.3 \%)$ & \multirow{7}{*}{$p<0.0001$} \\
\hline Hymenolepis spp. & $6(20 \%)$ & $15(50 \%)$ & $21(35 \%)$ & \\
\hline Strongyle & 0 & $17(56.7 \%)$ & $17(28.3 \%)$ & \\
\hline Oxyurid sp. & 0 & $2(6.7 \%)$ & $2(3.3 \%)$ & \\
\hline Strongyloides sp. & 0 & $5(16.7 \%)$ & $5(8.3 \%$ & \\
\hline Capillarid sp. & 0 & $1(3.3 \%)$ & $1(1.7 \%)$ & \\
\hline Total Helminths & $6(20 \%)$ & $24(80 \%)$ & $30(50 \%)$ & \\
\hline Single infection & $14(46.7 \%)$ & $4(13.3 \%)$ & $18(30 \%)$ & \multirow{6}{*}{$p<0.0001$} \\
\hline Mixed infection & $4(13.3 \%)$ & $26(86.7 \%)$ & $30(50 \%)$ & \\
\hline Duplet infection & $4(13.3 \%)$ & $7(23.3 \%)$ & $11(18.3 \%)$ & \\
\hline Triplet infection & 0 & $8(26.7 \%)$ & $8(13.3 \%)$ & \\
\hline Quadruplet infection & 0 & $9(30 \%)$ & $9(15 \%)$ & \\
\hline Pentuplet infection & 0 & $2(6.7 \%)$ & $2(3.3 \%)$ & \\
\hline
\end{tabular}


and some experiments involving coccidian morphology [15, $44]$, most of the studies are based on the histopathologic findings $[20,38,40-43,45]$, and in these contexts, it is not easy to compare our results with their investigations.

The diversity in parasite richness and parasitic concurrency, as measured by the parasitic prevalence, was higher in insectivores than in frugivores. This discrepancy might be explained based on different feeding habits and the landscapes of the habitat used. Landscapes include available diets, roosting sites, water sources, foraging habitats, and shared ecosystems with other animals. Firstly, insectivores usually prefer insects like bees, beetles, caddis flies, cockroaches, crickets, flies, flying ants, grasshopper, mayflies, mosquitoes, moths, termites, and wasps $[8,40,52]$. One or more of these insects are also known to act as intermediate hosts or transport vectors for helminth and or protozoan parasites [14, 53-58]. Secondly, insectivores mostly spend their lives in the caves with high moisture contents, which are essential for the survival and development of the eggs, cysts, oocysts, and larva of the GI parasites [59]. Thirdly, these bats usually spend the full day on roosts that can result in the evaporation and extreme loss of water from their body [60]. Therefore, after coming out of the roosts, they directly visit the water sources and drink water regularly to rehydrate themselves [61]. For foraging and drinking, most insectivores are known to utilize aquatic habitats like canals, farms, urban dams, lakes, streams, rivers, and swimming pools [62-65]. In the study areas, open defecation, nearby water sources, and fields were observed. Also, domestic animals like chicken, goats, cattle, dogs, and pigs of the study areas share the same water sources. They can contaminate them with infective cysts, eggs, oocysts, and larva of GI parasites. In these scenarios, we cannot ignore the possibility of cross-transmission of many parasites; although, further epidemiologic proofs are needed to confirm this opinion. In contrast to these bats, frugivores compensate for the requirement of water from plant/fruit juices and occasionally use the water sources [66, 67]. That is why they are less exposed to parasites.

In this research, compared with the frugivorous bats, the insectivorous bats possessed higher concomitant infections. Similar to our study, mixed infections by protozoa (Eimeria, Entamoeba, Giardia, and Cryptosporidium) and by protozoa and helminths (Ancylostomatidae, Vampirolepis nana) in Brazilian bats have been predominantly reported [34]. Concomitant infections are the rules rather than the exception [68], impact on the fitness of host as well as the epidemiology of the pathogens in all biological communities [68], and help investigate the role in the emergence of zoonoses [69]. Polyparasitism is the complex interactions among various species, and the outcome of those interactions can be synergistic (positive), antagonistic (negative), or neutral [68]. In positive case, the presence of one pathogen may enhance the infection by other pathogens. In negative case, one pathogen inhibits the infection or reproduction of other pathogens, for example, cats infected by many species possessed lower Toxocara loads [70]. In neutral case, there is no influence on infection by other pathogens. Our results of maximum coinfection by Eimeria in fecal samples suggest that further studies should be conducted to link this coccidian in GI pathogenesis. Nota- bly, the link of GI parasites in gastroenteritis has not been fully enlightened in a polyparasitized bat host. Thus, rather than single species, the effects of polyparasitism by enteric pathogen communities should be assessed especially in pathologic consequences [70,71].

It was interesting that Eimeria spp. were the predominant species in the insectivorous and overall bats. Their prevalence rate $(83.3 \%)$ in insectivores was lower than the findings from France (100\%) [37] and higher than reported from Europe (80\%) [72], the United States (75\%) [44], Brazil (74.07\%) [34], the United States (63.6\%) [15], Japan and North America $(3.4 \%-7 \%)[31,73]$, and Northwestern Arkansas (13\%) [15]. Similarly, the prevalence of Isospora sp. was $16.7 \%$ in the insectivorous bat, and this rate was slightly higher than the finding in the big brown insectivorous bats (Eptesicus fuscus) from the United States (4.92\%) [35]. Another important coccidian parasite detected in insectivores was Cryptosporidium with the prevalence of $10 \%$ which was slightly higher than the finding from China (7.7\%) [74] and the Philippines (8.8\%) [43] confirmed by molecular methods and slightly lower than the results from Brazil (11.11\%-16.3\%) [34, 75]. This coccidian parasite was also reported from the fecal samples of two insectivorous bats Pipistrellus pipistrellus and Myotis ciliolabrum via the molecular methods from the USA and Czech Republic [76] indicating these coccidia are predominant in bats.

Regarding Sarcodina, the prevalence of Entamoeba sp. was $30 \%$ in insectivores and $40 \%$ in frugivores suggesting both bats are critical reservoirs for this ameba. This prevalence was lower than that reported from Molossus molossus, an insectivorous bat in Brazil (32\%), and higher than that reported from two other insectivorous species like Myotis lavali (10\%) and Noctilio albiventris (21.05\%) [34]. Moreover, amebic dysentery caused by Entamoeba histolytica was firstly reported by techniques similar to ours and molecular assays in Rhinolophus rex, an insectivorous bat, from China indicating its pathologic consequences in bats [77].

Interestingly, only one sample (3.3\%) of insectivore was positive for Giardia sp. which was lower than reported in the similar hosts from Brazil (11.10\%) [34], indicating that this flagellate cannot be ignored during diagnosis of GI parasitism in bats.

Among the helminths, the overall prevalence of Hymenolepis spp. was the highest and was reported from both types of bats. The current prevalence of this tapeworm in insectivores (50\%) was slightly higher than the finding from Brazil (48.14\%) [34]. Similar genera have been predominantly reported from insectivores by other studies around the globe $[21,38-40,78,79]$. Some of these species include secondary hosts like insects in their life cycle. Thus, the current result indicates that parasite transmission is related to the feeding characteristics of the bat hosts, and it is the reason why the insectivorous bats were found to be positive with this cestode. Furthermore, we have reported the same genus of different morphotypes in the frugivorous bats, with a prevalence of $20 \%$. This rate was higher than that reported from Amazonia Brazil (1.49\%) in Artibeus planiros, a frugivorous bat [80].

In the current study, except for Hymenolepis spp., all other helminths like Ascarid spp., Strongyle, Oxyurid sp., Strongyloides sp., and Capillarid sp. were reported only from 
insectivores. We grouped three different morphotypes of nematode eggs into "Strongyle-type," because, without larval cultures, it is not easy to differentiate them only via the egg morphometry. Many previous histologic studies of GI tracts of the insectivorous bats from various geographies were conducted. They reported the presence of the adults of different Strongyles like Histostrongylus coronatus, Macuahuitloides inexpectans, Molinostrongylus ornatus, Parahistiostrongylus octacanthus, Strongylacantha glycyrrhiza, Torrestrongylus tetradorsalis, and Bidigiticauda serrafreire $[20,21,38,40,42,80-82]$. This evidence indicates the predominance of a wide variety of these nematodes.

There were two morphotypes of eggs of Ascarid spp. in the current insectivorous bats with the prevalence rates of $16.7 \%$, which was higher than the finding from Brazil [34]. This roundworm species was also reported in a few research findings $[83,84]$. Although we did not report these nematodes from frugivores, previous studies reported the presence of Toxocara pteropodis in frugivore bats from Australia [85], Palm Island (25\%) [86], and Sri Lanka (13\%) [87].

It was notable that in insectivores, we reported Strongyloides sp. with a prevalence of $16.7 \%$, which was slightly higher than reported from Brazil (9.25\%) [34]. Another nematode Capillarid sp. was reported to be present in 3.3\% insectivores, and this rate was similar to those reported from Brazil (1.49\%$3.7 \%)[34,80,88]$ and was lower than from Nigeria (18.44\%) [40]. This nematode was also reported in $2 \%$ frugivorous bats from Amazonian Brazil [67]. Interestingly, we found eggs of oxyurid nematodes in $6.7 \%$ of the insectivorous bats and are the first record in published peer-reviewed journals. The presence of this nematode may suggest two possible hypotheses; firstly, oxyurids are natural in bats. Secondly, bats may acquire them via cross-transmission from animal sources; importantly, cross-transmission is known to be highly prevalent among these hosts [89]. Cross-transmission of oxyurid in bats may occur via occasional feeding on rodent and avian species [7, 90].

\section{Conclusions}

In conclusion, the current study contributes to the understanding of GI parasites and their roles in disease according to their feeding habits. The study also suggests that compared to the frugivorous bats, the insectivorous bats have a wide and complex behavioral and ecologic landscape including the selection of insect diets, water bodies, and sharing of an ecosystem with other vertebrates which are critical for transmission of the parasitic species. Based on the wide diversity of parasite richness and parasitic concurrency measured by the prevalence rates, we suggest that GI parasitism might be a threatening factor in the insectivorous bats in the current study area. However, further detailed molecular and epidemiologic studies are essential to identify the species, to assess their pathology, and to analyze their host specificity to clarify their roles in threatening the bats.

\section{Data Availability}

All data generated or analyzed during this study are included within this article.

\section{Ethical Approval}

The authors declare that the study was conducted on naturally infected bats. No experimental infection was established during this research work. The required permission for the collection of the fecal samples was issued by Nepal Health Research Council (NHRC) Ethical Review Board (Permission number: 463/2018), Government of Nepal, Ministry of Forests and Environment, Department of Forestry (Permission number: 203/2018), District Forest Office (Permission number: 65/2018), Kalika Municipality (Permission number: 55/2018), and Veterinary Services, Kalika Municipality, Chitwan (Permission number: 05/2018).

\section{Conflicts of Interest}

The authors declare that they have no conflict of interest.

\section{Authors' Contributions}

Roshan Babu Adhikari conceived and designed the study as well as performed the field and laboratory works. Mahendra Maharjan supervised the work. Tirth Raj Ghimire investigated parasites in the laboratory, provided laboratory facilities, and analyzed data. All three authors wrote the manuscript and finalized it.

\section{Acknowledgments}

The authors would like to acknowledge Prof. Dr. Tej Bahadur Thapa, Head of Department, Central Department of Zoology, Tribhuvan University, Kathmandu, for permitting the dissertation works; Ms. Jaishree Sijapati, Chief, Faculty of Science, Nepal Academy of Science and Technology (NAST) for permitting the laboratory works in Animal Research Laboratory; Mr. Ganga Ram Regmi and Mr. Purna Ale, Third Pole Conservancy (TPC), Bhaktapur, for their supports in field works and in preparing GIS map; Nepal Health Research Council (NHRC), Government of Nepal for the ethical approval of the research; Ministry of Forests and Environment, Department of Forestry; District Forest Office, Chitwan; Kalika Municipality, and Kalika Municipality Veterinary Services for granting the permission of the works.

\section{Supplementary Materials}

Supplementary file 1: patterns of parasitic species in frugivorous and insectivorous bats. (Supplementary Materials)

\section{References}

[1] American Society of Mammalogists, Taxon Summary Statistics. Mammal Diversity DatabaseNovember 2019, https:// mammaldiversity.org/summary.

[2] S. Mickleburgh, K. Waylen, and P. Racey, "Bats as bushmeat: a global review," Oryx, vol. 43, no. 2, pp. 217-234, 2009.

[3] D. R. Prothero, The Princeton field guide to prehistoric mammals. Princeton Field Guides. Vol. 112, Princeton University Press, 2016. 
[4] K. E. Jones, N. G. Patel, M. A. Levy et al., "Global trends in emerging infectious diseases," Nature, vol. 451, no. 7181, pp. 990-993, 2008.

[5] I. Schwab and J. Pettigrew, "A choroidal sleight of hand," British Journal of Ophthalmology, vol. 89, no. 11, pp. 1398-1398, 2005.

[6] J. O. Whitaker Jr., "Chitinase in insectivorous bats," Journal of Mammalogy, vol. 85, no. 1, pp. 15-18, 2004.

[7] M. B. Fenton and T. H. Fleming, "Ecological interactions between bats and nocturnal birds," Biotropica, vol. 8, no. 2, pp. 104-110, 1976.

[8] M. B. Fenton and N. B. Simmons, Bats: A World of Science and Mystery, University of Chicago Press, 2015.

[9] P. W. Freeman, Form, function, and evolution in skulls and teeth of bats. Papers in Natural Resources, p. 9, 1998.

[10] L. Hammond, Bats: Biology and Behaviour, Oxford University Press, 1996.

[11] IUCN, The IUCN Red List of Threatened Species. Version 20192. 2019 23March 2020, http://www.iucnredlist.org.

[12] P. R. Acharya and L. A. Ruedas, The Bat Fauna of Nepal: A Current Conspectus, 2007, BAT NET NEWSLETTER.

[13] T. R. Ghimire, R. B. Adhikari, and G. R. Regmi, The zig-zag trail of symbiosis among Chepang, bat, and butter tree: an analysis of conservation threat in Nepal, in Wild plants: the Treasure of Natural Healers, M. Rai, S. Bhattarai, and C. M. Feitosa, Eds., CRC Press-Taylor and Francis Group, Boca Raton, Florida, 2020.

[14] C. D. Hilton and T. L. Best, Gastrointestinal helminth parasites of bats in Alabama. in Fourth colloquium on conservation of mammals in the southeastern United States. Occasional Papers of the North Carolina Museum of Natural Sciences and the North Carolina Biological Survey, North Carolina Museum of Natural Sciences, 2000.

[15] C. T. McAllister and S. J. Upton, "Two new species of Eimeria (Apicomplexa: Eimeriidae) from eastern red bats, Lasiurus borealis (Chiroptera: Vespertilionidae), in Arkansas and North Carolina," Journal of Parasitology, vol. 95, no. 4, pp. 991-993, 2009.

[16] M. E. Marshall and G. C. Miller, "Some digenetic trematodes from Ecuadorian bats including five new species and one new genus," The Journal of Parasitology, vol. 65, no. 6, pp. 909-917, 1979.

[17] C. McAllister, R. S. Seville, R. Arlen, and M. B. Connior, "A new species of Eimeria (Apicomplexa: Eimeriidae) from tricolored bats, Perimyotis subflavus (Chiroptera: Vespertilionidae), from the Ouachitas of Arkansas," Acta Parasitologica, vol. 59, no. 4, pp. 690-693, 2014.

[18] C. T. McAllister, R. S. Seville, and C. R. Bursey, "Helminth (Cestoda, Nematoda) and coccidian (Apicomplexa: Eimeriidae) parasites of the eastern small-footed myotis, Myotis leibii (Chiroptera: Vespertilionidae) from Arkansas, with a description of a new species of Eimeria," Acta Parasitologica, vol. 62, no. 2, pp. 377-381, 2017.

[19] F. Schär, U. Trostdorf, F. Giardina et al., "Strongyloides stercoralis: global distribution and risk factors," PLoS Neglected Tropical Diseases, vol. 7, no. 7, article e2288, 2013.

[20] Ž. Horvat, B. Čabrilo, M. Paunović et al., "The helminth fauna of the greater horseshoe bat (Rhinolophus ferrumequinum)(Chiroptera: Rhinolophidae) on the territory of Serbia," Biologia Serbica, vol. 37, no. 1-2, pp. 64-67, 2016.

[21] C. P. Santos and D. I. Gibson, "Checklist of the helminth parasites of South American bats," Zootaxa, vol. 3937, no. 3, pp. 471-499, 2015.
[22] IDML, Environmental Impact Assessment of Shaktikhor Industrial District, Chitwan. 2019, Industrial District Management Limited: Report Submitted to Government of Nepal, Ministry of Forests and Environment, Singh Durbar, Kathmandu, NepalIndustrial District Management Limited.

[23] A. Rijal, "Living knowledge of the healing plants: ethnophytotherapy in the Chepang communities from the MidHills of Nepal," Journal of Ethnobiology and Ethnomedicine, vol. 4, no. 1, p. 23, 2008.

[24] T. R. Ghimire and N. Bhattarai, "A survey of gastrointestinal parasites of goats in a goat market in Kathmandu, Nepal," Journal of Parasitic Diseases, vol. 43, no. 4, pp. 686-695, 2019.

[25] A. M. Zajac and G. A. Conboy, Veterinary Clinical Parasitology, John Wiley \& Sons, 2012.

[26] B. K. Baek, C. S. Kim, J. H. Kim, K. S. Han, and Y. G. Kim, "Studies on isosporosis in dogs. I: isolation and sporulation of Isospora ohioensis," The Korean Journal of Parasitology, vol. 31, no. 3, pp. 201-206, 1993.

[27] S. Edgar, "Effect of temperature on the sporulation of oocysts of the protozoan, Eimeria tenella," Transactions of the American Microscopical Society, vol. 73, no. 3, pp. 237-242, 1954.

[28] S. Edgar, "Sporulation of oocysts at specific temperatures and notes on the prepatent period of several species of avian coccidia," The Journal of Parasitology, vol. 41, no. 2, pp. 214-216, 1955.

[29] T. R. Ghimire, "Redescription of genera of family Eimeriidae Minchin, 1903," International Journal of Life Sciences, vol. 4, pp. 26-47, 2010.

[30] D. W. Duszynski, D. W. Reduker, and B. B. Parker, "Eimeria from bats of the world. II. A new species in Tadarida femorosacca from Sonora, Mexico," The Journal of Parasitology, vol. 74, no. 2, pp. 317-321, 1988.

[31] D. W. Duszynski, D. T. Scott, J. Aragon, A. Leach, and T. Perry, "Six new Eimeria species from vespertilionid bats of North America," The Journal of Parasitology, vol. 85, no. 3, pp. 496-503, 1999.

[32] D. W. Duszynski and S. J. Upton, "Coccidia (Apicomplexa: Eimeriidae) of the mammalian order Insectivora," Faculty Publications from the Harold W. Manter Laboratory of Parasitology, vol. 4, pp. 1-67, 2000.

[33] D. W. Duszynski and P. G. Wilber, "A guideline for the preparation of species descriptions in the Eimeriidae," The Journal of Parasitology, vol. 83, no. 2, pp. 333-336, 1997.

[34] V. F. S. Lima, P. A. Rocha, M. A. D. Silva et al., "Survey on helminths and protozoa of free-living Neotropical bats from Northeastern Brazil," Acta Tropica, vol. 185, pp. 267-272, 2018.

[35] A. Wünschmann, J. F. X. Wellehan Jr., A. Armien et al., "Renal infection by a new coccidian genus in big brown bats (Eptesicus fuscus)," Journal of Parasitology, vol. 96, no. 1, pp. 178$183,2010$.

[36] E. J. L. Soulsby, Helminths, arthropods and protozoa of domesticated animals seventh edition, Vol. 792, Affiliated East-West Press Private Limited, New Delhi, 2012.

[37] E. Afonso, P. E. Baurand, P. Tournant, and N. Capelli, "First amplification of Eimeria hessei DNA from the lesser horseshoe bat (Rhinolophus hipposideros) and its phylogenetic relationships with Eimeria species from other bats and rodents," Experimental Parasitology, vol. 139, pp. 58-62, 2014.

[38] K. Junker, O. Bain, and J. Boomker, "Helminth parasites of Natal long-fingered bats, Miniopterus natalensis (Chiroptera: 
Miniopteridae), South Africa," Onderstepoort Journal of Veterinary Research, vol. 75, no. 3, pp. 261-265, 2008.

[39] A. C. Falconaro, R. M. Vega, and G. P. Viozzi, "Helminth communities of two populations of Myotis chiloensis (Chiroptera: Vespertilionidae) from Argentinean Patagonia," International Journal for Parasitology: Parasites and Wildlife, vol. 7, no. 1, pp. 27-33, 2018.

[40] F. C. Okafor, I. Igbinosa, and H. Ezenwaji, "Helminth fauna of Tadarida (Chaeraphon) nigeriae (Thomas, 1913)(Microchiroptera: Molossidae)," Animal Research International, vol. 1, no. 1, pp. 64-69, 2008.

[41] J. S. Lord, S. Parker, F. Parker, and D. R. Brooks, "Gastrointestinal helminths of pipistrelle bats (Pipistrellus pipistrellus/Pipistrellus pygmaeus) (Chiroptera: Vespertilionidae) of England," Parasitology, vol. 139, no. 3, pp. 366-374, 2012.

[42] J. M. Caspeta-Mandujano, J. L. Peralta-Rodríguez, M. G. Galindo-García, and F. A. Jiménez, "A new species of Torrestrongylus (Trichostrongylidae, Anoplostrongylinae) from Macrotus waterhousii (Chiroptera: Phyllostomidae) in Central Mexico," Parasite, vol. 22, no. 29, pp. 28-29, 2015.

[43] F. Murakoshi, K. Koyama, T. Akasaka, N. Horiuchi, and K. Kato, "Molecular and histopathological characterization of Cryptosporidium and Eimeria species in bats in Japan," Journal of Veterinary Medical Science, vol. 80, no. 9, pp. 1395-1399, 2018.

[44] C. T. McAllister, R. S. Seville, and Z. P. Roehrs, "A new species of Eimeria (Apicomplexa: Eimeriidae) from the northern myotis, Myotis septentrionalis (Chiroptera: Vespertilionidae), in Oklahoma," The Journal of Parasitology, vol. 98, no. 5, pp. 5-1003, 2012.

[45] M. Saoud and M. Ramadan, "Studies on the helminth parasites of bats in Egypt and the factors influencing their occurrence with particular reference to digenetic trematodes," Zeitschrift für Parasitenkunde, vol. 51, no. 1, pp. 37-47, 1976.

[46] T. N. Petney and R. H. Andrews, "Multiparasite communities in animals and humans: frequency, structure and pathogenic significance," International Journal for Parasitology, vol. 28, no. 3, pp. 377-393, 1998.

[47] L. Drake and D. Bundy, "Multiple helminth infections in children: impact and control," Parasitology, vol. 122, no. S1, pp. S73-S81, 2001.

[48] F. Bordes and S. Morand, "The impact of multiple infections on wild animal hosts: a review," Infection Ecology and Epidemiology, vol. 1, no. 1, p. 7346, 2011.

[49] F. Bordes, S. Morand, and G. Ricardo, "Bat fly species richness in Neotropical bats: correlations with host ecology and host brain,” Oecologia, vol. 158, no. 1, pp. 109-116, 2008.

[50] Q. M. R. Webber and C. K. R. Willis, "Sociality, parasites, and pathogens in bats, in Sociality in Bats," Springer, Cham, 2016.

[51] J. E. Patterson and K. E. Ruckstuhl, "Parasite infection and host group size: a meta-analytical review," Parasitology, vol. 140, no. 7, pp. 803-813, 2013.

[52] G. Schalk and R. M. Brigham, "Prey selection by insectivorous bats: are essential fatty acids important?," Canadian Journal of Zoology, vol. 73, no. 10, pp. 1855-1859, 1995.

[53] M. R. Cranfield, H. Bixler, T. K. Graczyk, and R. Fayer, "House flies (Musca domestica) as transport hosts of Cryptosporidium parvum," The American Journal of Tropical Medicine and Hygiene, vol. 61, no. 3, pp. 500-504, 1999.

[54] T. K. Graczyk, R. Knight, and L. Tamang, "Mechanical transmission of human protozoan parasites by insects," Clinical Microbiology Reviews, vol. 18, no. 1, pp. 128-132, 2005.
[55] M. B. Markus, "Flies as natural transport hosts of Sarcocystis and other coccidia," Journal of Parasitology, vol. 66, no. 2, pp. 361-362, 1980.

[56] W. Kasprzak and A. Majewska, "Transmission of Giardia cysts. I. The role of flies and cockroaches," Wiadomosci Parazytologiczne, vol. 27, no. 4-5, pp. 555-563, 1981.

[57] A. A. Adenusi, M. I. Akinyemi, and D. Akinsanya, "Domiciliary cockroaches as carriers of human intestinal parasites in Lagos Metropolis, Southwest Nigeria: implications for public health," Journal of Arthropod-Borne Diseases, vol. 12, no. 2, pp. 141-151, 2018.

[58] R. Issa, "Musca domestica acts as transport vector hosts," Bulletin of the National Research Centre, vol. 43, no. 1, p. 73, 2019.

[59] A. Gajadhar, W. Scandrett, and L. Forbes, "Parásitos zoonóticos transmitidos por los alimentos y el agua en las granjas," Revue Scientifique et Technique, vol. 25, no. 2, pp. 595-606, 2006.

[60] P. Webb, J. Speakman, and P. Racey, "Evaporative water loss in two sympatric species of vespertilionid bat, Plecotus auritus and Myotis daubentoni: relation to foraging mode and implications for roost site selection," Journal of Zoology, vol. 235, no. 2, pp. 269-278, 1995.

[61] D. Russo, L. Cistrone, and G. Jones, "Sensory ecology of water detection by bats: a field experiment," PLoS One, vol. 7, no. 10, p. e48144, 2012.

[62] S. L. Jackrel and R. S. Matlack, "Influence of surface area, water level and adjacent vegetation on bat use of artificial water sources," The American Midland Naturalist, vol. 164, no. 1, pp. 74-79, 2010.

[63] F. Lisón and J. Calvo, "The significance of water infrastructures for the conservation of bats in a semiarid Mediterranean landscape," Animal Conservation, vol. 14, no. 5, pp. 533-541, 2011.

[64] I. Salvarina, "Bats and aquatic habitats: a review of habitat use and anthropogenic impacts," Mammal Review, vol. 46, no. 2, pp. 131-143, 2016.

[65] C. Sirami, D. S. Jacobs, and G. S. Cumming, "Artificial wetlands and surrounding habitats provide important foraging habitat for bats in agricultural landscapes in the Western Cape, South Africa," Biological Conservation, vol. 164, pp. 30-38, 2013.

[66] S. J. Ghanem, H. Ruppert, T. H. Kunz, and C. C. Voigt, "Frugivorous bats drink nutrient-and clay-enriched water in the Amazon rain forest: support for a dual function of mineral-lick visits," Journal of Tropical Ecology, vol. 29, no. 1, pp. 1-10, 2013.

[67] M. R. Nogueira, "Gastrointestinal helminth parasitism in fruiteating bats (Chiroptera, Stenodermatinae) from western Amazonian Brazil," Revista de Biología Tropical, vol. 52, no. 2, pp. 387-392, 2014.

[68] A. O. Hoarau, P. Mavingui, and C. Lebarbenchon, "Coinfections in wildlife: focus on a neglected aspect of infectious disease epidemiology," PLoS Pathogens, vol. 16, no. 9, article e1008790, 2020.

[69] A. J. Peel, K. Wells, J. Giles et al., "Synchronous shedding of multiple bat paramyxoviruses coincides with peak periods of Hendra virus spillover," Emerging microbes \& infections, vol. 8, no. 1, pp. 1314-1323, 2019.

[70] E. Serrano and J. Millán, "What is the price of neglecting parasite groups when assessing the cost of co-infection?," Epidemiology \& Infection, vol. 142, no. 7, pp. 1533-1540, 2014.

[71] S.-X. Zhang, Y. M. Zhou, W. Xu et al., "Impact of co-infections with enteric pathogens on children suffering from acute 
diarrhea in southwest China," Infectious Diseases of Poverty, vol. 5, no. 1, p. 64, 2016.

[72] E. Afonso, P. Tournant, J. C. Foltête et al., "Is the lesser horseshoe bat (Rhinolophus hipposideros) exposed to causes that may have contributed to its decline? A non-invasive approach," Global Ecology and Conservation, vol. 8, pp. 123$137,2016$.

[73] D. W. Duszynski, "Coccidia from bats (Chiroptera) of the world: a new Eimeria species in Pipistrellus javanicus from Japan," The Journal of Parasitology, vol. 83, no. 2, pp. 280282, 1997.

[74] W. Wang, L. Cao, B. He et al., "Molecular characterization of Cryptosporidium in bats from Yunnan province, southwestern China," Journal of Parasitology, vol. 99, no. 6, pp. 1148-1150, 2013.

[75] J. M. N. Batista, C. de Carvalho, W. A. Pedro et al., "Identification of Cryptosporidium bat genotypes XVI-XVIII in bats from Brazil," Parasitology Research, vol. 118, no. 7, pp. 21832191, 2019.

[76] M. Kváč, A. Hořická, B. Sak et al., "Novel Cryptosporidium bat genotypes III and IV in bats from the USA and Czech Republic," Parasitology Research, vol. 114, no. 10, pp. 3917-3921, 2015.

[77] G.-Z. He, Y. X. Chen, W. Y. Tian et al., "Entamoeba histolytica infections in a king horseshoe bat (Rhinolophus rex): a first case report," Asian Journal of Animal and Veterinary, vol. 6, no. 10, pp. 1026-1030, 2011.

[78] C. Vaucher, "Revision of the genus Vampirolepis Spasskij, 1954 (Cestoda: Hymenolepididae)," Memórias do Instituto Oswaldo Cruz, vol. 87, Supplement 1, pp. 299-304, 1992.

[79] A. M. F. Milano, Helmintofauna de murciélagos (Chiroptera) del nordeste argentino, in FACULTAD DE CIENCIAS NATURALES Y MUSEO, UNIVERSIDAD NACIONAL DE LA PLATA, 2016.

[80] A. C. A. de Albuquerque, M. F. D. Moraes, A. C. Silva, I. M. Lapera, J. H. Tebaldi, and E. G. Lux Hoppe, "Helminth fauna of chiropterans in Amazonia: biological interactions between parasite and host," Parasitology Research, vol. 115, no. 8, pp. 3229-3237, 2016.

[81] R. de Oliveira Simões, S. Fraga-Neto, E. M. Vilar, A. M. Júnior, and R. Val Vilela, "A new species of Bidigiticauda (Nematoda: Strongylida) from the bat Artibeus planirostris (Chiroptera: Phyllostomidae) in the Atlantic Forest and a molecular phylogeny of the Molineid bat parasites," Journal of Parasitology, vol. 105, no. 5, pp. 783-792, 2019.

[82] T. Genov, R. Stoykova-Hajinikolova, and F. Meszaros, "Molinostrongylus spp. (Nematoda: Molineidae) from bats in Bulgaria, with a review of European species," Parasitologia hungarica, vol. 25, pp. 53-68, 1992.

[83] J. Esteban, P. Botella, R. Toledo, and J. L. Oltra-Ferrero, "Helminthfauna of bats in Spain. IV. Parasites of Rhinolophus ferrumequinum (Schreber, 1774)(Chiroptera: Rhinolophidae)," Research and Reviews in Parasitology, vol. 59, no. 1-2, pp. 57-68, 1999.

[84] D. K. Jameson, "A survey of the parasites of five species of bats," The Southwestern Naturalist, vol. 4, no. 2, pp. 61-65, 1959.

[85] H. Baylis, "XXXIV.- - a new Ascarid from a bat," Annals and Magazine of Natural History, vol. 17, no. 99, pp. 360-365, 2009.
[86] D. E. Moorhouse, "Toxocariasis: a possible cause of the Palm Island Mystery Disease," Medical Journal of Australia, vol. 1, no. 4, pp. 172-173, 1982.

[87] A. C. Karawita, C. G. Himsworth, R. P. V. J. Rajapakse, T. K. Bollinger, and P. de S. Gunawardena, "Toxocara pteropodis in free-ranging Indian flying foxes (Pteropus medius) in Sri Lanka," Journal of Wildlife Diseases, vol. 53, no. 2, pp. 414416, 2017.

[88] É. M. d. Mello and R. J. D. Silva, "New records of capillariidae species (Nematoda, Enoplida) parasiting bats (Mammalia, Chiroptera) in Brazil," Neotropical Helminthology, vol. 13, no. 2, pp. 353-358, 2019.

[89] A. D. Luis, D. T. S. Hayman, T. J. O'Shea et al., "A comparison of bats and rodents as reservoirs of zoonotic viruses: are bats special?," Proceedings of the Royal Society B: Biological Sciences, vol. 280, no. 1756, p. 20122753, 2013.

[90] SMCRF, Bats of Nepal: a field guide, P. R. Acharya, H. Adhikari, S. Dahal, A. Thapa, and S. Thapa, Eds., Small Mammals Conservation and Research Foundation (SMCRF), Nepal, 2010. 